\title{
Polyphenolic profile characterization of Agrimonia eupatoria L. by HPLC with different detection devices
}

\author{
Helena Correia, ${ }^{1}$ Ana González-Paramás, ${ }^{2}$ Maria Teresa Amaral, ${ }^{1}$ Celestino Santos-Buelga ${ }^{2}$ and \\ Maria Teresa Batista ${ }^{1 *}$ \\ 'Laboratório de Farmacognosia, Faculdade de Farmácia and Centro de Estudos Farmacêuticos, Universidade de Coimbra, $3000-295$ Coimbra, \\ Portugal \\ Unidad de Nutrición y Bromatología, Facultad de Farmacia, Universidad de Salamanca, 37007 Salamanca, Spain
}

Received 17 March 2005; accepted 21 April 2005

\begin{abstract}
Liquid chromatography coupled to diode array and electrospray ionization mass spectrometry detection was used to establish the polyphenolic profile of an ethyl acetate fraction from Agrimonia eupatoria L. aqueous-alcoholic extract. Additionally, an HPLC technique with post-column derivatization by $p$-dimethylaminocinnamaldehyde was employed for the selective detection and quantification of flavan-3-ols. Important information was obtained by combining the data of these two HPLC techniques. Flavan-3-ols (catechin and procyanidins B1, B2, B3, B6, B7, C1, C2 and epicatechin-epicatechin-catechin), quercetin 3-Oglucoside, quercetin 3-O-galactoside, kaempferol 3-O-glucoside, kaempferol 3-O-(6"- $O$-p-coumaroyl)-glucoside, apigenin 6-Cglucoside and various phenolic acids were identified. Antioxidant activity of the Agrimonia eupatoria L. fraction containing these compounds was assessed through the 1,1-diphenyl-2-picrylhydrazyl, trolox equivalent antioxidant capacity and thiobarbituric acid reactive substances methods. Significant activity was observed for this fraction, where compounds with recognized antiinflammatory properties such as procyanidins, kaempferol 3- $O$-(6"- $O$ - $p$-coumaroyl)-glucoside and quercetin glycosides were identified for the first time. These results are predictive of the beneficial effects of this fraction, or some of its compounds, in human health, as possible anti-inflammatory drug. Copyright (C) 2005 John Wiley \& Sons, Ltd.
\end{abstract}

KEYWORDS: HPLC; diode array detection; ESI-MS/MS; post-column derivatization; Agrimonia eupatoria L.; polyphenols

\section{INTRODUCTION}

The aerial parts of agrimony (Agrimonia eupatoria L., Rosaceae) are used as infusions, decoctions or tinctures (aqueous-alcoholic extracts) in traditional medicine, for their anti-inflammatory, astringent and diuretic properties (Garnier et al., 1961; Newall et al., 1996). Nonetheless, only a small number of scientific investigations have been carried out concerning these activities and the constituents involved. Aromatic acids, triterpenes and tannins have been cited. The presence of kaempferide, kaempferol and their derivatives, such as kaempferol 3-glucoside, kaempferol 3-rhamnoside and kaempferol 3-rutinoside, have also been reported (Bilia et al., 1993). However, to our knowledge, very

\footnotetext{
*Correspondence to: M. T. Batista, Laboratório de Farmacognosia, Faculdade de Farmácia and Centro de Estudos Farmacêuticos, Universidade de Coimbra, 3000-295 Coimbra, Portugal.

E-mail: mtpmb@ci.uc.pt

Abbreviations used: ABTS, [2,2'-azinobis-(3-ethylbenzothiazoline6-sulfonic acid)]; DAD, diode array detection; DMACA, p-dimethylaminocinnamaldehyde; $\quad$ DPPH, (1,1-diphenyl-2picrylhydrazyl); TBARS, thiobarbituric acid reactive substances; TEAC, trolox equivalent antioxidant capacity.

Contract/grant sponsor: Fundação para a Ciência e Tecnologia.

Contract/grant sponsor: POCTI/FEDER.

Published online 24 June 2005

Copyright (c) 2005 John Wiley \& Sons, Ltd.
}

little scientific information has been published on the flavonoids, particularly on flavan-3-ols and its oligomers.

Flavonoids belong to the extensive group of polyphenols and several biological activities, such as anti-inflammatory, anti-ulcer, anti-cancer, antiviral, antibacterial, antispasmodic, neuroprotectant, antiatherosclerotic and anti-thrombotic, have been attributed to these compounds (Middleton et al., 2000). Oxidative stress and antioxidant defence imbalance have been associated with inflammatory, carcinogenic and coronary diseases. The recognized antioxidant potential of flavonoids could therefore be responsible for their beneficial actions (Pietta, 2000). An inverse relation between flavan-3-ols (monomeric and oligomeric) intake and ischemic heart disease and the incidence of cancers has also been found (Arts et al., 2001a,b). Moreover, anti-inflammatory properties, which are sometimes correlated with antioxidant activities, have also been verified (Mackenzie et al., 2004; Hosseini et al., 2001).

In the online polyphenolic characterization and quantification of complex biological matrices, HPLC/ diode array detection (DAD), in conjunction with mass spectrometry detection and post-column detection by derivatization with $p$-dimethylaminocinnamaldehyde 
(DMACA), plays an important role when oligomeric flavan-3-ols (proanthocyanidins) are present. These compounds have identical UV spectra. Furthermore, their low concentration in the extracts and their interference with other phenolic compounds make proanthocyanidins difficult to analyse by HPLC/DAD. HPLC/DAD/ESI-MS/MS and HPLC/DMACA were usefully applied to study proanthocyanidins from unripened sweet almond fruits and grape seed (de Pascual-Teresa et al., 1998a,b). In this work, the purpose was to use those two techniques as valuable tools to establish the polyphenolic profile of one medicinal plant, Agrimonia eupatoria L., and to verify its correlation with antioxidant activity, in support of the traditional use of this medicinal plant as an anti-inflammatory.

\section{EXPERIMENTAL}

\section{Samples}

The aerial parts of Agrimonia eupatoria L. were collected, dried and provided by Segredo da Planta, Portugal. Dr J. Paiva, of the Botany Department, identified the plant and a voucher specimen has been deposited at the Department of Pharmacognosy of the Faculty of Pharmacy, University of Coimbra (Portugal).

\section{Standards}

Different procyanidins (B1, B2, B3, B6, B7, C1, C2 and EEC) were isolated from either grape seeds or unripe fruits of almond (Prunus amygdalus) as previously described (de Pascual-Teresa et al., 1998a). Protocatechuic, $p$-coumaric and ascorbic acids, and catechin were purchased from Sigma. Apigenin 6- $C$-glucoside (isovitexin), quercetin 3- $O$-glucoside (isoquercitrin), quercetin 3-O-galactoside (hyperoside), kaempferol 3-O-glucoside and kaempferol 3-O-(6"-O-pcoumaroyl)-glucoside (tiliroside) were purchased from Extrasynhese.

\section{Extracts}

The extracts (infusion and tincture) were prepared according to the usages in traditional medicine. The tincture (the most active extract) was prepared by adding $30 \mathrm{~mL}$ of $45 \%$ aqueous ethanol to $2 \mathrm{~g}$ of the pulverized agrimony and leaving to stand for 13 days in the dark. Subsequently, the aqueousalcoholic extract was filtered and concentrated under vacuum to a volume of $10 \mathrm{~mL}$. An aliquot of this extract was washed with $n$-hexane to eliminate the fat-soluble compounds and fractionated by repeated extraction with ethyl acetate. The organic phases, containing the polyphenols, were collected, dehydrated with anhydrous sodium sulfate and concentrated with water, in a rotavapor at $30^{\circ} \mathrm{C}$, until all the ethyl acetate had been removed. The aqueous-alcoholic extract and the respective ethyl acetate fraction were frozen with liquid $\mathrm{N}_{2}$ and freeze-dried.

\section{Phytochemical characterization}

High-performance liquid chromatography (HPLC), using double online detection with a diode array spectrophotometer and a mass spectrometer (MS), was used to characterize the phenolic profile in the ethyl acetate fraction of the Agrimonia eupatoria L. aqueous-alcoholic extract. HPLC using detection after post-column derivatization with $p$ dimethylaminocinnamaldehyde (HPLC/DMACA) was performed for further flavan-3-ols analysis.

HPLC/DAD/MS. The analyses were performed on an HP 1100 liquid chromatography system interfaced with a Finnigan LCQ mass spectrometer equipped with an API-ES ionization chamber.

Separation was carried out in a $3 \mu \mathrm{m}$ Waters Spherisorb ODS 2 column $(150 \times 4.6 \mathrm{~mm})$ at $25^{\circ} \mathrm{C}$. The mobile phase consisted of $2.5 \%$ aqueous acetic acid (solvent $\mathrm{A}$ ), a mixture of acetonitrile-2.5\% aqueous acetic acid, 10:90 (solvent B) and acetonitrile (solvent $\mathrm{C}$ ). The gradient profile used was 0-5 min, $0-100 \% \mathrm{~B}$; $5-30 \mathrm{~min}, 0-15 \% \mathrm{C}$ in $\mathrm{B} ; 30-35 \mathrm{~min}$, $15-50 \% \mathrm{C}$ in $\mathrm{B} ; 35-40 \mathrm{~min}, 50 \% \mathrm{C}$ in $\mathrm{B}$ isocratically. The flow rate was $0.5 \mathrm{~mL} / \mathrm{min}$. The first detection was made in the diode array spectrophotometer using 280 and $360 \mathrm{~nm}$ as preferred wavelengths, followed by a second detection in the mass spectrometer. The capillary temperature and voltage were $225^{\circ} \mathrm{C}$ and $45 \mathrm{~V}$, respectively. Mass spectra were obtained in positive ion mode and the MS was programmed to perform a series of two scans: a full mass and an MS-MS of the most abundant ion.

HPLC/DMACA post-column derivatization detection. A Waters 600E HPLC system coupled to an auto sampler Waters 717 plus was used with the conditions previously described (de Pascual-Teresa et al., 1998b). First, detection at $280 \mathrm{~nm}$ was carried out in a diode array detector (HewlettPackard HP $1040 \mathrm{M}$ series II). Thereafter, the reagent (1\% DMACA in $1.5 \mathrm{~m}$ sulphuric acid in methanol) was added and the product of the reaction was measured at $640 \mathrm{~nm}$ in a UV-vis detector (Shimadzu SPD-10AV). Data treatment was performed on an HP data treatment station.

The flavan-3-ols were quantified by comparison of the areas of the peaks recorded at $640 \mathrm{~nm}$ with a calibration curve obtained with a standard of catechin.

\section{Antioxidant activity}

Antioxidant activity of the extracts was monitored using the DPPH (1,1-diphenyl-2-picrylhydrazyl) method. The DPPH, trolox equivalent antioxidant capacity (TEAC) and thiobarbituric acid reactive substances (TBARS) methods were used to evaluate the antioxidant activity of the aqueousalcoholic extract and the ethyl acetate fraction. All the assays were performed at least in triplicate.

Antiradical activity assays. Antiradical activity was assessed by the DPPH method (Blois, 1958). Briefly, different concentrations of samples $(100 \mu \mathrm{L})$ were added to $500 \mu \mathrm{L}$ of DPPH $(500 \mu \mathrm{M})$ in ethanol. After $30 \mathrm{~min}$, the absorbance was measured at $517 \mathrm{~nm}$ in a Hitachi U-2000 spectrophotometer. Scavenger activities were expressed in $\mathrm{EC}_{50}$ (micrograms of freeze-dried samples required to scavenge $50 \%$ of the DPPH 
radical). The ascorbic acid and the catechin $\mathrm{EC}_{50}$ were determined and used as reference.

Cation radical ABTS [2,2'-azinobis-(3-ethylbenzothiazoline6-sulfonic acid)] scavenging activity was measured by TEAC assay (Miller et al., 1993). The samples $(8.4 \mu \mathrm{L})$ were mixed with $30 \mu \mathrm{L}$ of ABTS radical $(5 \mathrm{~mm})$. The absorbance was monitored at $734 \mathrm{~nm}$ for 6 min using a Hewlett Packard 8453 spectrophotometer. The results were compared with Trolox C (water-soluble analogue of vitamin E) and expressed as TEAC per $\mu \mathrm{g}$ freeze-dried samples.

Lipid peroxidation assay. This method measures the thiobarbituric acid reactive substances that result from the lipid peroxidation (Plumb et al., 1998). Various concentrations of the sample $(4 \mu \mathrm{L})$ were added to an ascorbate/iron-induced peroxidation solution of phosphatidylcoline in absolute ethanol (final concentration $1.25 \mathrm{mg} / \mathrm{mL}$ ). The mixture was added to $800 \mu \mathrm{L}$ of TBA [trichloroacetic acid $20 \%(\mathrm{w} / \mathrm{v})$, thiobarbituric acid $0.4 \%$ (w/v), hydrochloric acid $0.25 \mathrm{M}$ ] and the lipid peroxidation was evaluated at $535 \mathrm{~nm}$ using a UV-vis Perkin-Elmer spectrophotometer model Lambda 3B. The results were expressed in $\mathrm{IP}_{50}(\mu \mathrm{g}$ freeze-dried samples required to inhibit $50 \%$ of the induced lipid peroxidation).

\section{Total phenols}

A modified version of the Folin-Ciocalteu method (Wang et al., 1997) was used. Absorbance was measured at 700 and $735 \mathrm{~nm}$ in a Hitachi U-2000 spectrophotometer and the results expressed as grams of gallic acid equivalents by $100 \mathrm{~g}$ freeze-dried samples. All samples were analysed in triplicate.

\section{Total flavonols}

Reagent $\left[\mathrm{AlCl}_{3} \cdot 6 \mathrm{H}_{2} \mathrm{O} 2 \%\right.$ in methanol (w/v), $\left.2 \mathrm{~mL}\right]$ was added to the samples in ethanol $(2 \mathrm{~mL})$. The absorbance was meas- ured after $10 \mathrm{~min}$, at $430 \mathrm{~nm}$ (Lamaison and Carnat, 1990) in a Hitachi U-2000 spectrophotometer, and the results were expressed in grams rutin equivalents by $100 \mathrm{~g}$ of freeze-dried samples. All samples were analysed in triplicate.

\section{RESULTS}

\section{Phytochemical characterization}

Figure 1 shows the HPLC profile recorded at $280 \mathrm{~nm}$ of the ethyl acetate fraction. Absorption spectra obtained with the diode array detector allowed most peaks to be identified as polyphenols, i.e. flavan-3-ols, flavonols (kaempferol and quercetin derivatives), flavones and phenolic acids. Table 1 summarizes the retention time and the UV and mass spectra characteristics obtained in the HPLC/DAD/ESI-MS/MS analysis, and, on this basis, the identification of the polyphenols present in the fraction. To our knowledge, no information has yet been published about flavan-3-ols in Agrimonia eupatoria L.

Flavan-3-ols. In order to characterize the flavan-3-ols present in the Agrimonia eupatoria L. ethyl acetate fraction, HPLC-MS chromatograms for the molecular ions $[\mathrm{M}+\mathrm{H}]^{+}$at $m / z$ 291, 579, 867 and 1155 were recorded. Thus, the occurrence of one (epi)catechin monomer and various procyanidin dimers (five), trimers (six) and tetramers (four), as the more representative flavan-3-ols, was detected.

A characteristic fragmentation pattern was observed in the $\mathrm{MS}^{2}$ spectra of the flavan-3-ols, showing signals corresponding to the retro Diels Alder fission (RDA;

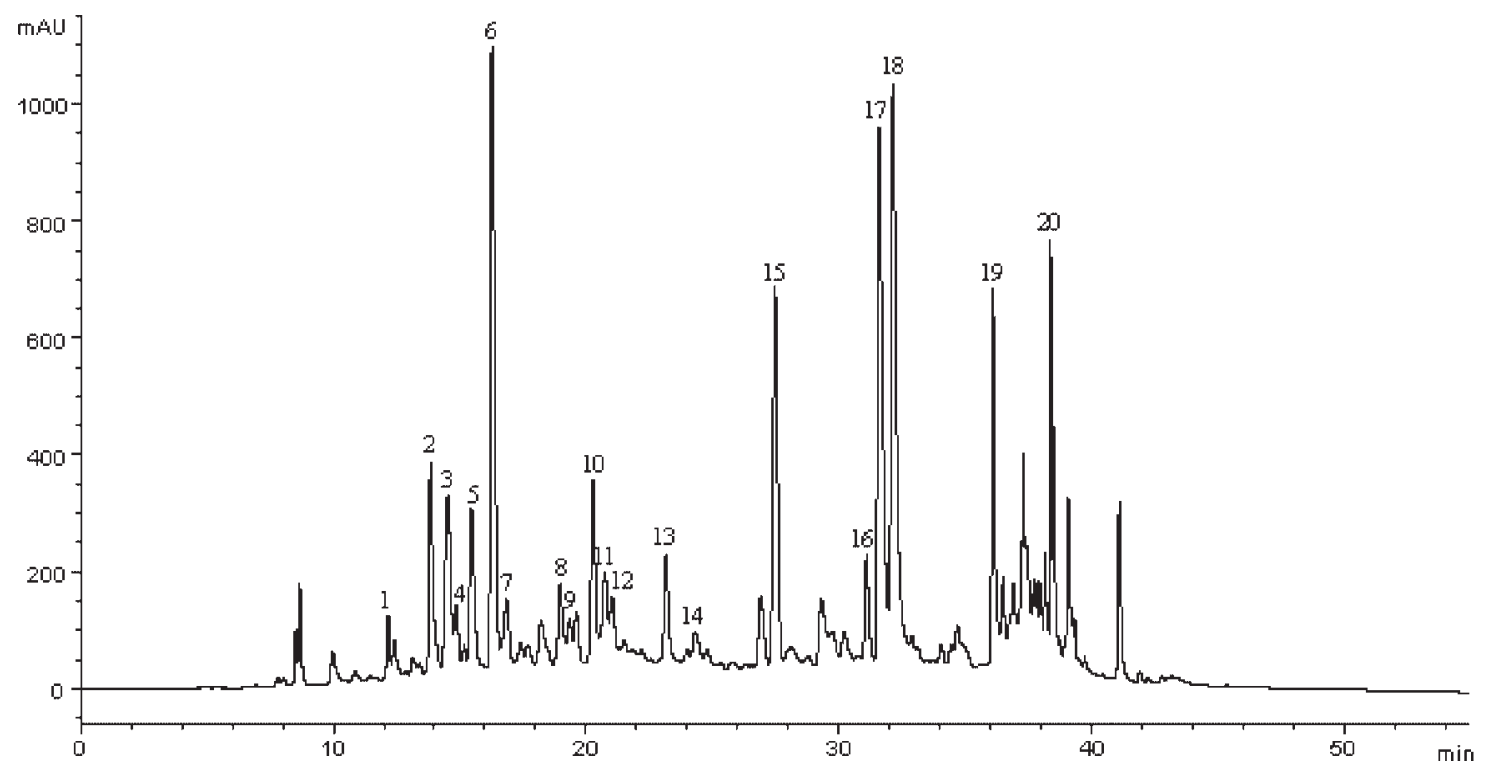

Figure 1. HPLC polyphenolic profile of an ethyl acetate fraction of Agrimonia eupatoria L., recorded at $280 \mathrm{~nm}$. The identification of the peaks is shown in Table 1. 
Table 1. UV-vis and MS spectra, and identification of the compounds of Agrimonia eupatoria L. ethyl acetate fraction

\begin{tabular}{|c|c|c|c|c|c|}
\hline \multirow{2}{*}{\multicolumn{2}{|c|}{ Compounds }} & \multirow[b]{2}{*}{$\begin{array}{c}\mathrm{Rt} \\
(\mathrm{min})\end{array}$} & \multirow[b]{2}{*}{$\begin{array}{l}\text { HPLC-DAD } \\
\quad(\mathrm{nm})\end{array}$} & \multicolumn{2}{|r|}{ HPLC-ESIMS } \\
\hline & & & & $\begin{array}{l}\text { Molecular ion } \\
{[\mathrm{M}+\mathrm{H}]^{+}(\mathrm{m} / z)}\end{array}$ & $\begin{array}{c}{[\mathrm{M}+\mathrm{H}]^{+} \text {fragments }} \\
[\mathrm{m} / \mathrm{z} \text { (relative abundance, } \%)]\end{array}$ \\
\hline 1 & Protocatechuic acid & 12.17 & 260,294 & - & - \\
\hline 2 & Procyanidin dimer B1 & 13.85 & 280 & 579 & 427 (99), 409 (100), 291 (27), 287 (37) \\
\hline 3 & Procyanidin dimer B3 & 14.54 & 280 & 579 & 453 (13), 427 (99), 409 (100), 291 (12), 287 (17) \\
\hline 4 & Procyanidin trimer & 14.87 & 280,330 sh & 867 & 697 (17), 577 (100), 409 (15), 287 (20) \\
\hline 5 & Procyanidin trimer $\mathrm{C} 2$ & 15.48 & 280 & 867 & 715 (90), $697(76), 577(57), 427$ (52), $409(100), 287$ (20 \\
\hline 6 & Catechin & 16.27 & 280 & 291 & $273(8), 165(86), 139(100), 123(81)$ \\
\hline 7 & Procyanidin trimer EEC & 16.86 & - & 867 & 715 (19), 697 (42), $577(31), 571$ (100), $427(16), 409$ (53) \\
\hline 8 & Procyanidin dimer B2 & 18.99 & $292 \mathrm{sh}, 310$ & 579 & $\begin{array}{l}561(12), 453(26), 435(50), 427 \text { (25), } 409 \text { (100), } 291 \text { (13), } \\
287 \text { (17) }\end{array}$ \\
\hline 9 & Procyanidin dimer B6 & 19.35 & 280,340 & 579 & $561(8), 453(67), 427(41), 435(88), 409$ (100), $287(40)$ \\
\hline 10 & Procyanidin trimer & 20.28 & 298sh, 324 & 867 & $\begin{array}{l}715(28), 714(100), 696(70), 579(29), 533(90), \\
427(23), 409(28), 287(21)\end{array}$ \\
\hline 11 & Procyanidin tetramer & 20.75 & 288,310 & 1155 & - \\
\hline 12 & Procyanidin trimer & 21.04 & 280 & 867 & 715 (9), 697 (37), 577 (100), 517 (47), 287 (12) \\
\hline 13 & Procyanidin dimer B7 & 23.16 & 280 & 579 & $435(28), 427(65), 409(100), 291(17), 287(27)$ \\
\hline 14 & Procyanidin trimer $\mathrm{C} 1$ & 24.32 & 278 & 867 & $714(53), 697(29), 589(68), 438(100), 427(7), 409(80)$ \\
\hline 15 & $p$-Coumaric acid & 27.48 & 298sh, 310 & - & - \\
\hline 16 & Apigenin $6-C$-glucoside & 31.10 & 270,338 & 433 & $\begin{array}{l}415(59), 397(40), 379(36), 367(100), 337(68), \\
313(33), 283(22), 271(2), 343(2)\end{array}$ \\
\hline 17 & Quercetin 3-O-galactoside & 31.60 & $\begin{array}{l}256,266 \mathrm{sh} \\
294 \mathrm{sh}, 354\end{array}$ & 465 & $303(100), 285(15), 257(44), 229(11)$ \\
\hline 18 & Quercetin 3-O-glucoside & 32.13 & $\begin{array}{l}256,264 \mathrm{sh} \\
298 \mathrm{sh}, 354\end{array}$ & 465 & $\begin{array}{l}303(100), 447(49), 429(28), 399(66), 376(26), \\
369(42), 345(21)\end{array}$ \\
\hline 19 & Kaempferol 3-O-glucoside & 36.11 & 265,294 sh, 348 & 449 & $\begin{array}{l}431(69), 413 \text { (41), } 395 \text { (27), } 383 \text { (72), } 353 \text { (84), } 329 \text { (79), } \\
299 \text { (22), } 287 \text { (100) }\end{array}$ \\
\hline 20 & $\begin{array}{l}\text { Kaempferol 3-O- }\left(6^{\prime \prime}-O-p-\right. \\
\text { coumaroyl }) \text {-glucoside }\end{array}$ & 38.50 & $268,314,348 \mathrm{sh}$ & 595 & $\begin{array}{l}576(39), 565(84), 489(59), 473(89), 459(57), 447(39), \\
443(100), 433(43)\end{array}$ \\
\hline
\end{tabular}

-152 m.u.), loss of water (-18 m.u.), RDA + water loss $(-170$ m.u.), loss of ring A (-126 m.u.), cleavage of the upper heterocyclic ring (C-ring; -246 m.u.) and/or cleavage of the interflavanic bond following the quinone-methide mechanism (-288 m.u.) (Fig. 2).

Spectral and chromatographic (retention time) characteristics of the detected flavan-3-ols are included in Table 1. Compound identification was based on their mass spectra (molecular ion and fragmentation pattern), chromatographic behaviour (elution order) and comparison with procyanidin standards previously isolated in the laboratory. The degree of polymerization does not significantly influence the elution, although the lower subunit and the interflavanic linkage are critical factors. Compounds with an epicatechin unit in the lower position or possessing $(4 \rightarrow 6)$ interflavanic linkage(s) usually elute later than the corresponding catechin derivatives and $(4 \rightarrow 8)$-linked procyanidins, respectively (Table 1 ).

Some UV results show interference between different phenolic compounds. Characteristic mass spectra of flavan-3-ols were obtained, although the UV spectra match with different compounds, mainly phenolic acids or their derivatives. Since the ionization of these compounds in these ESI conditions is poor, the co-elution observed does not constitute a problem for the flavan3-ols identification.
With a molecular ion at $m / z, 291$, compound 6 was identified as the monomer catechin. The elution and mass and UV characteristics were the same as those of the catechin standard. Dimeric procyanidins, compounds 2, 3, 8, 9 and 13, with molecular ions at $m / z 579$ were identified as type B procyanidins: epicatechin$(4 \beta \rightarrow 8)$-catechin (B1), catechin- $(4 \beta \rightarrow 8)$-catechin (B3), epicatechin- $(4 \beta \rightarrow 8)$-epicatechin $(\mathrm{B} 2)$, catechin- $(4 \beta \rightarrow 6)$ catechin (B6) and epicatechin- $(4 \beta \rightarrow 6)$-catechin (B7), respectively. Identification of procyanidins B1, B2 and B3 was confirmed by comparison with standards. The B6 and B7 identification was supported in their elution characteristics. The fragmentation profile of these dimers shows an unusual ion at $\mathrm{m} / \mathrm{z}$ 287, which might be the result of an oxidation reaction that produces another quinone structure (Rohr et al., 2000). Trimers and tetramers were also found in Agrimonia eupatoria L. ethyl acetate fraction, although the absence of standards and the lack of information relating to the order of elution only allowed the identity of compounds 5, $\mathbf{7}$ and $\mathbf{1 4}$ to be suggested as the procyanidin trimers catechin- $(4 \rightarrow 8)$-catechin- $(4 \rightarrow 8)$-catechin $(\mathrm{C} 2)$, epicatechin- $(4 \rightarrow 8)$-epicatechin- $(4 \rightarrow 8)$-catechin (EEC) and epicatechin- $(4 \rightarrow 8)$-epicatechin- $(4 \rightarrow 8)$-epicatechin (C1), respectively.

To confirm the identification and to quantify the flavan-3-ols, a post-column derivatization HPLC/ 


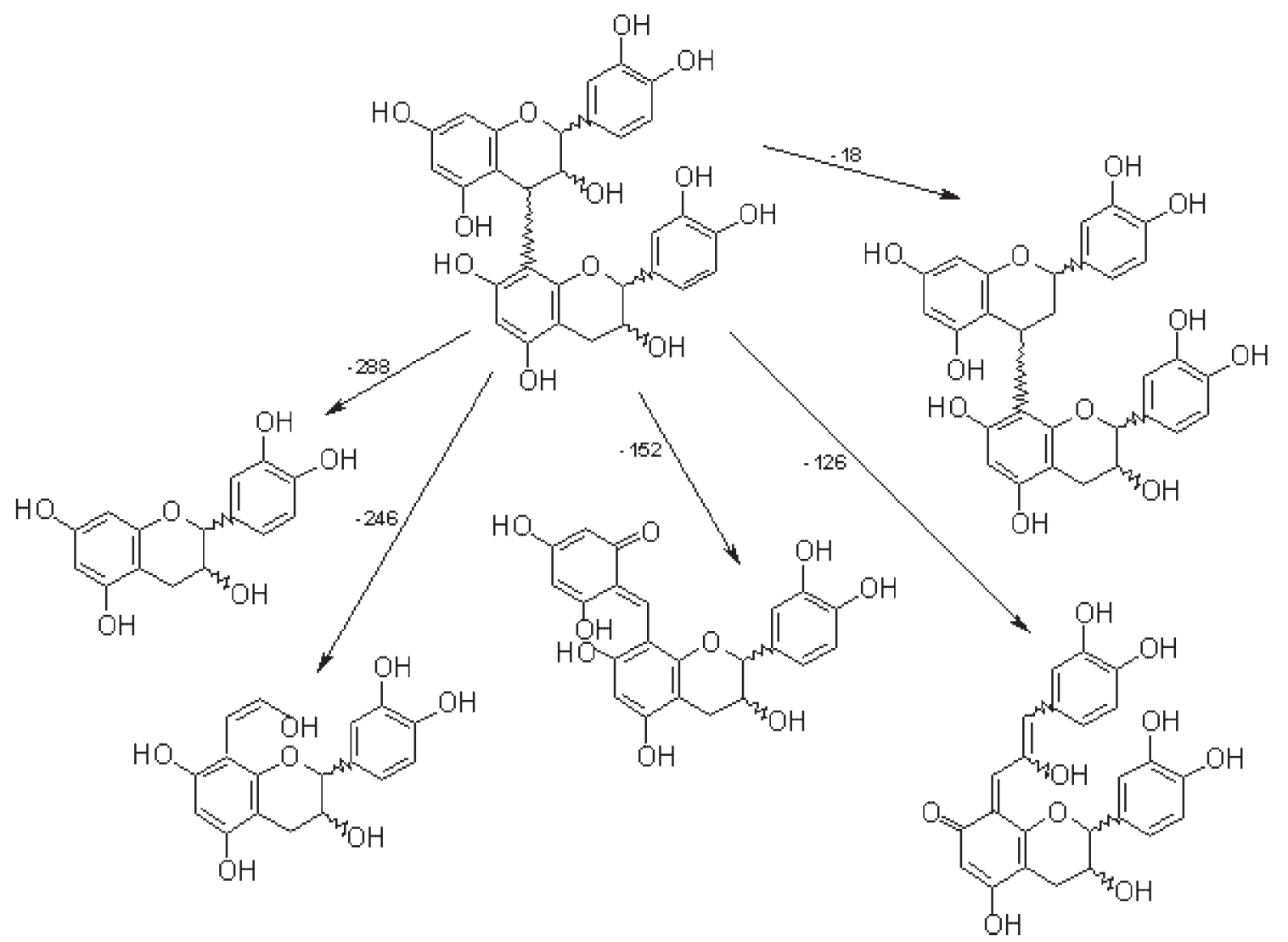

Figure 2. Characteristic fragments of procyanidins in the positive ionization mode.

DMACA method was used. The coloured complex, resulting from the reaction between the DMACA and the flavan-3-ols, shows a distinctive maximum at $640 \mathrm{~nm}$, thus overcoming co-elution with other compounds and allowing selective detection and rigorous quantification of the flavan-3-ols.

For identification, the chromatographic behaviour and the ratio between the areas of the peaks recorded at 640 and $280 \mathrm{~nm}\left(A_{640} / A_{280}\right)$ were considered according to Treutter et al. (1994). Individual quantification of compounds was made from the areas of their peaks recorded at $640 \mathrm{~nm}$ by comparison with a calibration curve prepared with catechin. Total flavanols, calculated as the sum of the concentrations of the individual flavan-3-ols, represented $18.96 \%$ of the freeze-dried ethyl acetate fraction, of which $6.34 \%$ corresponded to the monomer (catechin), 5.81\% to dimers (B1, 1.86\%; $\mathrm{B} 3,1.38 \%$; $\mathrm{B} 6,0.35 \%$; and $\mathrm{B} 7,1.63 \%)$ and $1.07 \%$ to the trimer EEC.

Flavones and flavonols. One flavone and four flavonols were identified in the Agrimonia eupatoria L. ethyl acetate fraction. Preliminary analysis of the compound $16 \mathrm{UV}$ spectrum suggested the presence of an apigenin derivative. The mass spectrum of this compound showed a molecular ion at $\mathrm{m} / \mathrm{z}, 33 \mathrm{~nm}$, releasing a wide range of $\mathrm{MS}^{2}$ fragments, one of them at $\mathrm{m} / \mathrm{z}$ 271 , related to apigenin, and others at $\mathrm{m} / z, 283,313$ and 343 , which correspond to the losses of 150,120 and 90 mass units. These fragments are due to the cross-ring cleavages that occurred in the sugar unit and are characteristic of the flavone C-hexoses (Bakhtiar et al., 1994; Sanchez-Rabaneda et al., 2003). This assumption was corroborated by the losses of one, two and three water moieties (fragments at $m / z, 415,397$ and 379) that are more intense than the ions resulting from the sugar cleavage (Grayer et al., 2000). According to these features and by its retention time, compared with a commercial standard, compound $\mathbf{1 6}$ was proposed to be the apigenin 6 - $C$-glucoside (isovitexin).

Compounds $\mathbf{1 7}$ and $\mathbf{1 8}$ were identified as quercetin derivates according to their UV spectra and the existence in their MS $^{2}$ spectra of a fragment at $\mathrm{m} / \mathrm{z}$ 303 , corresponding to quercetin aglycon. Retention characteristics and comparison with standards allowed compounds $\mathbf{1 7}$ and $\mathbf{1 8}$ to be identified as quercetin 3$O$-galactose (hyperoside) and quercetin 3-O-glucoside (isoquercitrin), respectively.

According to their UV spectra, compounds $\mathbf{1 9}$ and $\mathbf{2 0}$ were associated with kaempferol derivatives. The mass spectra of compound $\mathbf{1 9}$ showed a molecular ion at $\mathrm{m} / \mathrm{z}$ 449 and a fragment at $m / z, 287$, indicating kaempferol 
Table 2. Antioxidant activity and polyphenolic content of the Agrimonia eupatoria L. aqueous-alcoholic extract and ethyl acetate fraction

\begin{tabular}{|c|c|c|c|c|c|}
\hline & $\begin{array}{c}\mathrm{DPPH} \\
\left(\mathrm{EC}_{50}\right)\end{array}$ & TEAC & $\begin{array}{l}\text { TBARS } \\
\left(\mathrm{IP}_{50}\right)\end{array}$ & Total phenols & Total flavonols \\
\hline & \multicolumn{3}{|c|}{$\mu \mathrm{g}$} & \multicolumn{2}{|c|}{ (g \% \pm S.D.) } \\
\hline Tincture $^{a}$ & 18.120 & 0.196 & 15.078 & $15.780 \pm 2.931$ & $1.853 \pm 0.000$ \\
\hline $\mathrm{EtOAc}^{\mathrm{a}}$ & 9.800 & 0.608 & 2.122 & $27.637 \pm 2.060$ & $2.353 \pm 0.000$ \\
\hline
\end{tabular}

${ }^{a}$ Results expressed in freeze-dried samples.

linked to a hexose moiety. Comparison with a standard confirmed the compound identity as kaempferol 3-Oglucoside. The molecular ion of compound $\mathbf{2 0}$ was 146 m.u. greater than that of compound 19. In its UV spectrum, an additional absorption maximum was observed at $314 \mathrm{~nm}$, which is consistent with a $p$ coumaroyl moiety. Its later elution with regard to peak 19 is also coherent with the presence of such an acyl substituent. Based on these characteristics and comparison with a commercial standard, compound $\mathbf{2 0}$ was identified as kaempferol 3-O-(6"-O-p-coumaroyl)glucoside (tiliroside).

\section{Antioxidant activity}

Table 2 show the scavenger activities (DPPH and TEAC assays), the lipid peroxidation inhibition (TBARS assay) and the phenolic content (total phenols and flavonols) obtained for the Agrimonia eupatoria L. aqueous-alcoholic extract and its respective ethyl acetate fraction. The relevant content of phenols and significant antioxidant activity was observed for the aqueous-alcoholic extract. Its DPPH radical scavenge activity was quite similar to that obtained for ascorbic acid $\left(\mathrm{EC}_{50}=17 \mu \mathrm{g}\right)$ and much higher than that achieved for catechin $\left(\mathrm{EC}_{50}=140 \mu \mathrm{g}\right)$. Both antioxidant activity and phenolic content were appreciably increased in the ethyl acetate fraction, suggesting a straight relation between them.

\section{DISCUSSION AND CONCLUSION}

Evidence of a relevant antioxidant activity for the ethyl acetate fraction of Agrimonia eupatoria L. aqueousalcoholic extract (about double that of ascorbic acid) was found by the DPPH method (Table 2). Several polyphenols were identified in this fraction (Table 1), which probably contribute to or are responsible for that activity. Indeed, significant antioxidant activity has been ascribed to quercetin, kaempferol and flavone glycosides and to flavan-3-ols (Rice-Evans et al., 1996). In the Agrimonia eupatoria L. ethyl acetate fraction, the flavan-3-ols are present at a high percentage
$(18.96 \%)$. Catechin is the main individual compound (6.34\%) among them, although catechin-type oligomers (i.e. procyanidins) are the most representative flavan-3ols in the fraction. The difference between the antioxidant activity of a catechin standard and that of the fraction $\left(\mathrm{EC}_{50}=140\right.$ and $9.8 \mu \mathrm{g}$, respectively, by the DPPH method) was considerable, indicating the involvement of other compounds in the fraction antioxidant activity besides catechin. Proanthocyanidins, namely procyanidins, have relevant antioxidant properties and other important activities: anti-inflammatory effects, inhibition of platelet aggregation, metal complexation and protein interactions have also been attributed to them (Li et al., 2001; Santos-Buelga and Scalbert, 2000). It is believed that some of these properties, namely anti-inflammatory, are associated with the antioxidant activities of these compounds.

Valuable antioxidant and anti-inflammatory activities have been referred to kaempferol 3-O-(6"-O-pcoumaroyl)-glucoside, quercetin 3-O-galactoside and quercetin 3-O-glucoside (Sala et al., 2003; Melzig et al., 2001), which are also important constituents in the Agrimonia eupatoria L. ethyl acetate fraction. Moreover, hepatoprotective properties were also attributed to tiliroside, as well as to kaempferol 3-O-glucoside (Matsuda et al., 2002), which is also present in the studied fraction.

Studies in vivo suggest that the catechin and smaller oligomeric procyanidins can be absorbed (Cos et al., 2004). The intestinal absorption of quercetin glycosides, namely quercetin 3-O-glucoside, has also been reported (Crespy et al., 2001).

In conclusion, compounds that had not been previously reported in Agrimonia eupatoria L., but with recognized biological activities and bioavailability, were detected in this medicinal plant by the combination of two HPLC techniques, one of which shows high specificity for flavanols. This study provided very important information for targeting the potentially active compounds of Agrimonia eupatoria L. The compounds identified can contribute to explaining the beneficial effects of this plant on human health. The high antioxidant activity registered is also predictive that such beneficial biological properties could be related, at least 
in part, to its reported anti-inflammatory activity in traditional medicine.

\section{Acknowledgements}

The authors would like to thank the Fundação para a Ciência e Tecnologia (FCT) and POCTI/FEDER for their financial support. The authors are also grateful to 'Segredo da Planta', Portugal, for the provision of the plant, to Dr J. Paiva for the plant classification and to Dr José Joaquín Pérez-Alonso for technical assistance.

\section{REFERENCES}

Arts IC, Hollman PC, Feskens EJ, Bueno de Mesquita HB and Kromhout D. Catechin intake might explain the inverse relation between tea consumption and ischemic heart disease: the Zutphen Elderly Study. American Journal of Clinical Nutrition 2001a; 74: 227.

Arts IC, Hollman PC, Bueno de Mesquita HB, Feskens EJ and Kromhout D. Dietary catechins and epithelial cancer incidence: the Zutphen Elderly Study. International Journal of Cancer 2001b; 92 298.

Bakhtiar A, Gleye J, Moulis C and Fourasté I. Desorption chemical ionization mass spectrometry of $\mathrm{C}$-glycosylflavones. Phytochemical Analysis 1994; 5: 86.

Bilia AR, Palme E, Catalano S, Pistelli L and Morelli I. Constituents and biological assay of Agrimonia eupatoria. Fitoterapia 1993; LXIV: 549 .

Blois MS. Antioxidant determinations by the use of a stable free radical. Nature 1958; 181: 1199.

Cos P, de Bruyne T, Hermans N, Apers S, Vanden Berghe D and Vlietinck AJ. Proanthocyanidins in health care: current and new trends. Current Medical Chemistry 2004; 11: 1345.

Crespy V, Morand C, Besson C, Manach C, Démigné C and Rémésy C. Comparison of the intestinal absorption of quercetin, phloretin and their glucosides in rats. Journal of Nutrition 2001; 131: 2109.

de Pascual-Teresa S, Gutiérrez-Fernández Y, Rivas-Gonzalo JC and Santos-Buelga C. Characterization of monomeric and oligomeric flavan-3-ols from unripe almond fruits. Phytochemical Analysis 1998a; 9: 21.

de Pascual-Teresa S, Treutter D, Rivas-Gonzalo JC and SantosBuelga C. Analysis of flavanols in beverages by high-performance liquid chromatography with chemical reaction detection. Journal of Agriculture and Food Chemistry 1998b; 46: 4209.

Garnier G, Bézanger-Beauquesne L and Debraux G. Ressource Médicinales de la Flore Française. Paris: Vigot Frères Éditeurs, 1961; 727.

Grayer RJ, Kite GC, Aboud-Zaid M and Archer L. The application of atmospheric pressure chemical ionization liquid chromatography-mass spectrometry in the chemotaxonomic study of flavonoids: characterization of flavonoids from Ocimum gratissimum var. gratissimum. Phytochemical Analysis 2000; 11: 257.

Hosseini S, Pishnamazi S, Sadrzadeh SMH, Farid F, Farid R and Watson RR. Pycnogenol ${ }^{\circledR}$ in the management of asthma. Journal of Medicine and Food 2001; 4: 201.
Lamaison JL and Carnat A. Teneur en principaux flavonoides des fleurs et des feuilles de Crataegus monogyna Jacq. et de Crataegus laevigata (Poiret) D.C. (Rosaceae). Pharmaceutica Acta Helvetica 1990; $65: 315$.

Li WG, Zhang XY, Wu YJ and Tian X. Anti-inflammatory effect and mechanism of proanthocyanidins from grape seeds. Acta Pharmacologica Sinica 2001; 22: 1117.

Mackenzie GG, Carrasquedo F, Delfino JM, Keen CL, Fraga CG and Oteiza PI. Epicatechin, catechin, and dimeric procyanidins inhibit PMA-induced NF- $\kappa \mathrm{B}$ activation at multiple steps in Jurkat T cells1. FASEB Journal 2004; 168: 167.

Matsuda $H$, Ninomiya $K$, Shimoda $H$ and Yoshikawa $M$. Hepatoprotective principles from the flowers of Tilia argentea (Linden): structure requirements of tiliroside and mechanisms of action. Bioorganic Medical Chemistry 2002; 10: 707.

Melzig MF, Pertz $\mathrm{HH}$ and Krenn L. Anti-inflammatory and spasmolytic activity of extracts from Droserae herba. Phytomedicine 2001; 8: 225.

Middleton E, Jr., Kandaswami C and Theoharides TC. The effects of plant flavonoids on mammalian cells: implications for inflammation, heart disease, and cancer. Pharmacology Review 2000; 52 673.

Miller NJ, Rice-Evans C, Davies MJ, Gopinathan V and Milner A. A novel method for measuring antioxidant capacity and its application to monitoring the antioxidant status in premature neonates. Clinical Science (London) 1993; 84: 407.

Newall CA, Anderson LA and Phillipson JD. Herbal Medicines-A Guide of Health-Care Professionals. London: The Pharmaceutical Press, 1996; 21.

Pietta PG. Flavonoids as antioxidants. Journal of Natural Products 2000; 63: 1035 .

Plumb GW, de Pascual-Teresa S, Santos-Buelga C, Cheynier V and Williamson G. Antioxidant properties of catechins and proanthocyanidins: effect of polymerization, galloylation and glycosylation Free Radical Research 1998; 29: 351.

Rice-Evans CA, Miller NJ and Paganga G. Structure-antioxidant activity relationships of flavonoids and phenolic acids. Free Radical Biology and Medicine 1996; 20: 933.

Rohr GE, Riggio G, Meier B and Sticher O. Evaluation of different detection methods modes for the analysis of procyanidins in leaves and flowers of Crataegus spp. Part II. Liquid chromatography-mass spectrometry. Phytochemical Analysis 2000; 11: 113.

Sala A, Recio MC, Schinella GR, Máñez S, Giner RM, CerdáNicolás M and Ríos JL. Assessment of the anti-inflammatory activity and free radical scavenger activity of tiliroside. European Journal of Pharmacology 2003; 461: 53.

Sanchez-Rabaneda F, Jauregui O, Casals I, Andres-Lacueva C Izquierdo-Pulido $\mathrm{M}$ and Lamuela-Raventos RM. Liquid chromatographic/electrospray ionization tandem mass spectrometric study of the phenolic composition of cocoa (Theobroma cacao). Journal of Mass Spectrometry 2003; 38: 35.

Santos-Buelga C and Scalbert A. Proanthocyanidins and tannin-like compounds-nature, occurrence, dietary intake and effects on nutrition and health. Journal of Science in Food and Agriculture 2000; 80: 1094.

Treutter D, Santos-Buelga C, Gutmann M and Kolodziedj H. Identification of flavan-3-ols and procyanidins by high-performance liquid chromatography and chemical reaction detection. Journal of Chromatography A 1994; 667: 290

Wang C-K, Lee W-H and Peng C-H. Contents of phenolics and alkaloids in Areca catechu Linn. during maturation. Journal of Agriculture and Food Chemistry 1997; 45: 1185. 